\title{
The Relationship between Corporate Governance and Stakeholder Engagement, and Materiality Disclosure in Sustainability Reporting
}

\author{
${ }^{1}$ Sie Bing Ngu and ${ }^{2}$ Azlan Amran \\ ${ }^{1}$ School of Business and Administration, Disted College, Malaysia \\ ${ }^{2}$ Graduate School of Business, Universiti Sains Malaysia, Malaysia
}

Correspondence Author: Sie Bing Ngu, Disted College, 340 Jalan Macalister, 10350 George Town, Penang,

E-mail: sbngu@disted.edu.my, siebing2000@hotmail.com.

Received date: 12 January 2018, Accepted date: 10 March 2018, Online date: 20 March 2018

Copyright: (c) 2018 Sie Bing Ngu and Azlan Amran. This is an open-access article distributed under the terms of the Creative Commons Attribution License, which permits unrestricted use, distribution, and reproduction in any medium, provided the original author and source are credited.

\begin{abstract}
This paper proposes a conceptual framework by linking corporate governance, stakeholder engagement, and materiality disclosure in sustainability reporting from the perspective of stakeholder theory. The quality of materiality disclosure in sustainability reporting is argued to be a function of the board attributes as sustainability disclosure practices emanate from the board of directors. Good corporate governance and materiality disclosure are corporate good practices in enhancing their relations with stakeholders. Reporting on materiality information by having stakeholder engagement provides greater transparency and achieves greater accountability to the stakeholders. However, discussion on this topic is lacking in Malaysia. Hence, this paper aims to fill in this gap and to broaden corporate governance research by proposing the mediating effect of stakeholder engagement on corporate governance and materiality disclosure in sustainability reporting. The contribution of this paper is to link the materiality concept and stakeholder engagement in sustainability reporting as well as to extend the academic literature on sustainability reporting.
\end{abstract}

Key words: Corporate Governance, Stakeholder Engagement, Materiality, Sustainability Reporting

\section{INTRODUCTION}

Traditionally, corporate social responsibility (CSR) refers to the responsibility of businesses to act ethically and consider their social and environmental impact on the community. However, CSR does not necessarily encompass sustainability. In recent years, many leading global companies have moved beyond CSR. CSR looks back at performance, typically over the past 12 months, while sustainability concerns preserving resources, and a more prominent forwardlooking focus, with the aim of securing the future for trading.

Since the Brundtland [1] report on sustainable development, the issues of environmental, social and governance (ESG), and the pursuit of sustainable development have become increasingly important in both the private sector and the public sector. Stakeholders require greater accountancy and transparency than before. In response to the needs of stakeholders, many companies have attempted to provide information for stakeholders by complementing traditional financial reporting through the reporting of non-financial information [2]. This non-financial information is normally reported in the form of a separate stand-alone sustainability report, which is separate from a company's annual report [3].

Sustainability reporting is defined as the reporting practice of measuring and disclosing the long-term and short-term social and environmental performance of the company, which supports it in controlling its business operations and ensures accountability to stakeholders in a more sustainable way [4-5]. Sustainability reporting is used by many companies to communicate to stakeholders about their ESG activities and business performance to demonstrate the contribution of companies towards sustainable development [6]. Sustainability reporting is also used by companies as a communication channel that aims to influence the public perception and enhance the image or reputation of the company [7]. Companies can embed sustainability considerations in their business strategy, and leverage sustainability to reduce risk and take advantage of business opportunities [8].

However, sustainability reports are usually produced in isolation, and, thus, lack a holistic and complete picture of the business as a whole. GreenBiz [9] highlighted that materiality was one of the top four sustainability reporting trends in 2014. Materiality is a fairly new concept in the sustainability reporting field [10] and is an essential filter for determining whether the information is considered important and useful to stakeholders [11].

Based on the stakeholder theory, it is vital for companies to enact stakeholder engagement processes to create and enhance corporate legitimacy. Corporate legitimacy guarantees the capital, labour, and customer inflow for the financial viability of the company [12]. To ensure corporate legitimacy, companies must adopt a 'materiality' approach in defining the content of reporting and report on those issues that are considered material [4-5] from the viewpoint of stakeholders, and that are critical to the achievement of the goals of the company. Sustainability reports are not fully accountable and credible to stakeholders unless companies engage stakeholders during the materiality assessment process. Therefore, the process of stakeholder engagement is necessary for understanding the needs and expectations of diverse stakeholders.

Past research examined the internal determinants of financial and non-financial disclosure, particularly focusing on corporate characteristics, such as industry, size, and financial performance as well as the external determinants, especially the general contextual factors, such as socio-political systems, legislation, country, and culture. Adams [13] highlighted that the academic literature has been lagging behind regarding the internal contextual factors that may drive corporate disclosure, such as board composition, board structure, board leadership, and board characteristics.

Many research investigated the impact of corporate governance on financial disclosure and sustainability disclosure. Prior studies claimed that financial and sustainability disclosure practices emanate from the board of directors [14-15] as the board of directors constitutes primary corporate governance mechanism. Board members can use sustainability disclosure as part of the dialogue between the company and its stakeholders, by providing information on the social and 
environmental activities that legitimize company behaviour, and change the perceptions and expectations of stakeholders [16]. Good corporate governance and sustainability disclosure can be seen as complementary mechanisms to enhance the relations between the company and its stakeholders [17]. Based on this argument, this paper claims that the corporate governance characteristics are the fundamental determinant of materiality disclosure in sustainability reporting. In a departure from past studies, this paper focuses on Malaysian companies and addresses corporate governance and stakeholder engagement, and how they affect the materiality disclosure in sustainability reporting.

In past years, although many studies examined the connections between corporate governance and sustainability reporting, they did not explore one element the mediating effect of stakeholder engagement on the relationship between corporate governance and materiality disclosure in sustainability reporting. Therefore, the aim of this paper is to contribute to the academic literature by establishing the linkage between corporate governance, stakeholder engagement, and materiality disclosure in sustainability reporting.

The remainder of the paper is organized as follows. The second section reviews the literature that has been examined in previous studies. This is followed by the underpinning theory in the third section. The proposed conceptual framework is introduced in the fourth section, which is based on the stakeholder theory to explain the relationship between corporate governance and stakeholder engagement, and materiality disclosure in sustainable reporting. Finally, the fifth section concludes the paper.

\section{Literature Review:}

Materiality Disclosure in Sustainability Reporting:

The materiality concept is from the field of financial accounting [18] and is becoming increasingly important in sustainability reporting (non-financial reports) [11]. Whitehead [19] noted that while financial materiality and sustainability materiality both involve identifying the most important issues, they differ in respect of their intended audience. In the financial context, materiality is used to determine whether an item is significant enough to be included in a financial report. In other words, financial materiality focuses on issues that are important to investors, while sustainability materiality has a broader scope that considers issues that are important to all stakeholders [11].

A few authors adopted quantitative methods for assessing the materiality of the sustainability indicators [20-21]. Unerman and Zappettini [10] also highlighted that it is important to take materiality into consideration. They argued that materiality must be taken into consideration when researchers seek to interpret the lack of disclosure of particular social and environmental issues. Hsu, Lee and Chao [21] constructed an optimal model to identify the material issues to be included in the sustainability reporting of the Lite-On Technology Corporation in Taiwan. Edgley [22] examined the materiality from the perspective of assurors. They focused on how assurors make sense of sustainability materiality, and how it differs from financial audit materiality. They analysed the interplay between the old and new logic that are shaping materiality as a reporting concept in social and environmental reporting.

In a more recent study, Bing and Amran [23] provided a comprehensive review of the academic literature on board diversity and materiality disclosure in sustainability reporting from the perspective of governance. Fasan and Mio [24] examined the factors influencing the materiality disclosure in integrated reporting among International Integrated Reporting Council Pilot Programme companies. The results indicated that industry, board size, and board diversity played an important role in the materiality disclosure; however, they found no relationship between legal environment and materiality disclosure. Puroila [25] explored the application of the materiality concept, as well as the point of view through which the issue is considered as material to achieve a greater understanding of materiality in sustainability reporting.

In a departure from previous studies, the aim of this paper is to introduce the materiality concept in sustainability reporting. Materiality disclosure in sustainability is the dependent variable in this paper. Research in this context is still lacking in Malaysia.

\section{Corporate Governance:}

Corporate governance is the system of the procedural, structural, and cultural safeguards that are designed to ensure that a company takes responsibility for directing and controlling its business affairs in a way that is accountable and transparent to its shareholders and stakeholders [26]. The alignment requires the commitment of a company and its stakeholders to sustain interactions. Corporate governance and company responsibility became a topic of debate due to the causes of the ASEAN economic crisis in 1997. Said, Zainuddin and Haron [27] suggested that one of the ways to solve the issue is to deal with corporate governance. The discussion about the role of board and the strength of diversity had been discussed in the Bing and Amran [23]. In Malaysia, the focus on corporate governance can be attributed to the Cadbury Report of 1992.

According to Kolk [26], sustainability reporting and corporate governance merge when a company starts to report both issues in one report. This arises when the issues become related because of the combined efforts of accountability or when corporate governance starts to include social, environmental and ethical concerns, and sustainability reporting covers the accountability structure. In addition, Kolk [26] asserted that companies nowadays are increasingly using both sustainability reporting and corporate governance to achieve greater accountability to their stakeholders. The materiality determination process can be seen to confirm such convergence, as it requires companies to frame their corporate governance and to disclose their material issues accordingly [24].

Positioning and governing sustainability within the company is the key to its successful alignment with the company strategy. Companies with a strong corporate governance culture will be better positioned to manage sustainability risks and opportunities. In order to embed sustainability considerations in company strategy, accountability should be at the highest level, i.e., the board. Board-level commitment is crucial as it is the board that sets the strategic direction of the company. Such commitment is also important for ensuring that sustainability is embedded across the company and that, adequate resources, systems, and processes are in place for managing sustainability issues. Strong support from the board of directors and high-level discussions in relation to materiality are a crucial step in identifying and prioritizing sustainability issues that are material [8].

This paper differs from previous studies by examining the relationship between corporate governance and materiality disclosure in sustainability reporting based on a broader view that encompasses the perspective of stakeholders rather than only the viewpoint of shareholders. Therefore, the objective is to broaden corporate governance research by examining how corporate governance influences the materiality disclosure in sustainability reporting.

\section{Stakeholder Engagement:}

Stakeholders refer to individuals, groups, or companies that can affect or be affected by corporate decisions [28]. The types of stakeholders involved in a large company include customers, suppliers, employees, shareholders, community, and governmental bodies. Stakeholder engagement can be defined as the collaborative or participative actions that stakeholders undertake for the purpose of assisting a company in solving the social and environmental problems, and in developing a proactive social and environmental strategy [29].

In recent years, companies have begun to recognize the importance of stakeholder engagement as part of the reporting process in the private and public sectors, and as an overall interactive mechanism [30]. Companies are increasingly shifting towards stakeholder engagement to enhance greater transparency and accountability to stakeholders, and also to provide better communication concerning the impact of their sustainability activities on society at large. Additionally, stakeholder engagement could enhance the mutual trust, understanding and alignment between companies and their stakeholders [31]. Moreover, successful stakeholder engagement and the objective determination of materiality are important in reporting the sustainability drive of companies [32].

Yusoff and Darus [33] contended that stakeholder engagement was crucial for maintaining a sustainable business, and for ensuring that 'green' initiatives and performance were communicated. They argued that stakeholder engagement signifies that companies recognize the strategic importance of sustainability reporting and its related activities in creating long-term wealth for their shareholders and stakeholders. In addition, Adams and Larrinaga-Gonzallez [16] asserted that the stakeholder engagement was a fundamental part of the sustainability reporting process of companies. The authors argued that stakeholder engagement had the potential to become a powerful determinant for change, because its aim was to challenge the role of the company in terms of social and environmental reporting. Moreover, Manetti [34] also highlighted that stakeholder engagement was a crucial step in the sustainability reporting process, because its aim was to define the materiality and relevance information communicated

This paper differs from prior studies by examining the mediating effect of stakeholder engagement on corporate governance and materiality disclosure in sustainability reporting. Empirical research in this context is lacking in Malaysia. Hence, this paper contributes by helping to fill this gap. 
Corporate Governance and Stakeholder Engagement:

The primary corporate governance mechanism is that of board members as their primary purpose is to protect the interests of the shareholders and stakeholders. Boards play a central role in identifying the risks and opportunities for companies, in particularly, sustainability disclosure [24]. In this respect, the sustainability disclosure policies emanating from board members aim to legitimize the activities of the company to meet the diverse needs and expectations of stakeholders. A company manages legitimacy by providing a signal to the stakeholders that the behaviour of the company is appropriate and desirable. The company uses sustainability disclosure as a business strategy to respond to the expectations of the stakeholders.

Sustainability reporting can increase the transparency and accountability to stakeholders [35] which helps build and maintain trust between the stakeholders and the companies [36]. To understand the demands of stakeholders, stakeholder engagement is essential for sustainability reporting because it assists in identifying the material and relevant information, needs, and expectations of different stakeholders in relation to the sustainability issues [37]. Stakeholder engagement is used consistently among listed companies in disclosing their material issues to stakeholders [38].

\section{Stakeholder Engagement and Materiality Disclosure in Sustainability Reporting:}

The stakeholder theory emphasizes that effective management of stakeholder relationships is important as it may mitigate the likelihood of negative legislative, regulatory, or fiscal actions, while protecting and enhancing the corporate reputation $[28,39]$. Therefore, companies have increasingly recognized the importance of identifying the expectations of different stakeholders to formulate a suitable approach for meeting their expectations.

The principle of materiality and relevance in the sustainability context contends that engaging stakeholders during the materiality determination process will enable the board members to determine which information is considered material and should be included in the social and environmental reporting [40]. International standards and guidelines require stakeholder engagement as a compulsory stage in sustainability reporting to obtain useful and complete sustainability reports for the targeted users [37, 41].

\section{Corporate Governance, Stakeholder Engagement and Materiality Disclosure in Sustainability Reporting:}

Solomon and Solomon [42], pointed out that active stakeholder engagement represents an important corporate governance mechanism, which can be used to influence corporate governance in areas such as social, environmental, and ethics. Cornell and Shapiro [43] used the stakeholder to suggest that companies have contracts with their stakeholders, and that company value depends on the ability of the companies to fulfil these contracts [43]. Effective stakeholder engagement is an important requirement for the success of a company. Therefore, board members, as representatives of shareholders, play a central role in overseeing the creation and implementation of the management plans to balance the interests and expectations of a wide range of stakeholders [44].

Based on the stakeholder theory, this study explores the indirect effect of stakeholder engagement through the lens of corporate governance on materiality disclosure in sustainability reporting. This indirect relationship is considered to be important since boards can actively involve stakeholders during the materiality determination process to achieve the disclosure of greater material information in the sustainability reports. The examination of this indirect relationship has been neglected in past literature.

\section{Underpinning Theory:}

The stakeholder theory was developed by Freeman [28] and has been used almost exclusively from a company perspective. In recent years, the focus of the stakeholder theory has moved from stakeholder management towards stakeholder engagement. Stakeholder engagement is a network-based, relational, and process-oriented approach $[30,45]$.

Scholars of the stakeholder theory have classified the relational models between companies and stakeholders into three phases that assume a gradual growth path in terms of the involvement of stakeholders. Firstly, is stakeholder mapping, in which companies identify their key stakeholders by distinguishing between the primary stakeholders and the secondary stakeholders. The primary stakeholders are able to determine company survival, whereas secondary stakeholders can influence or are influenced by the company but do not influence the sustainability of the business [46]. Secondly, is stakeholder management, in which companies try to manage the expectations of stakeholders, as well as the social and economic issues [34]. Thirdly, is stakeholder engagement, this is where companies involve their stakeholders in the decision-making processes, sharing of information, making stakeholders participants in the management of the business and dialogue, and creating a business model of mutual trust, respect, and responsibility [34].

The stakeholder engagement phase is different to stakeholder mapping and stakeholder management in that it foresees a mutual understanding and commitment to resolve the problems that may arise in the relations between the companies and the stakeholders. Therefore, stakeholder engagement is an interaction process that can create a dynamic dialogue, mutual respect, and change management between companies and stakeholders [45].

The stakeholder theory has been used to explain the reporting activity in previous studies [24, 47]. The stakeholder theory supports the disclosure of material information [48] and suggests that the board of directors, being the major control mechanism in the company, is both responsible and accountable to a wider group of stakeholders [49]. Thus, the stakeholder theory is used in this paper to support the conceptual framework by linking the relationship between corporate governance and stakeholder engagement, and materiality disclosure in sustainability reporting.

\section{Proposed Conceptual Framework:}

Based on the literature review above, a conceptual framework is proposed based on the stakeholder theory, as shown in Figure 1. This paper proposes that there is a linkage between corporate governance and stakeholder engagement, and materiality disclosure in sustainability reporting.

Figure 1 shows that stakeholder engagement mediates the relationship between corporate governance and materiality disclosure in sustainability reporting. Board members play a central role in influencing sustainability disclosure and are accountable to a wide range of stakeholders. Reporting on material sustainability information provides greater transparency and achieves greater accountability to the stakeholders.

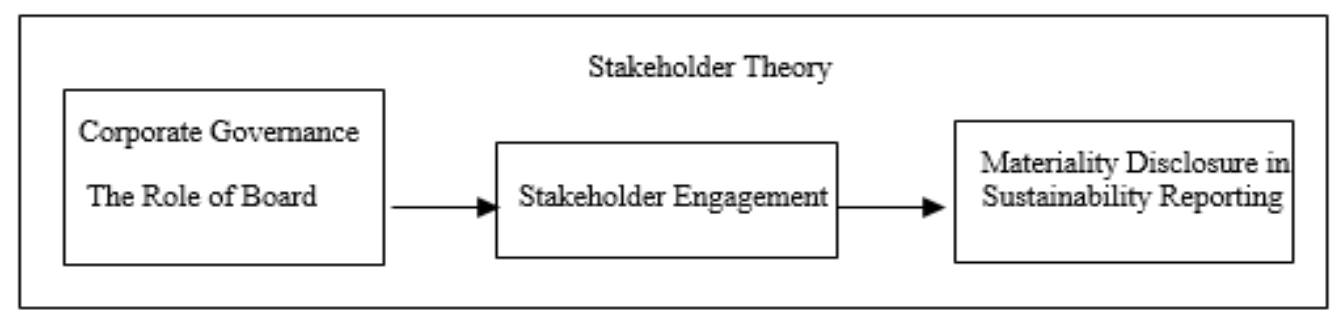

\section{Fig. 1: Proposed Conceptual Framework}

\section{Conclusion:}

Given that sustainability reporting is one of the most important types of reporting in relation to company sustainability, an in-depth assessment of materiality disclosure in sustainability reporting is necessary to meet the demands of stakeholders.

From a theoretical standpoint, this paper contributes to the previous academic literature by proposing a model based on the stakeholder theory. The proposed model is for examining the influence of corporate governance on materiality disclosure, and to explore the mediating role of stakeholder engagement between corporate governance and materiality disclosure in sustainability reporting. From the stakeholder theory perspective, reporting on the material aspects of sustainability information provides greater transparency and achieves greater accountability for the stakeholders.

One of the most important practical implications of this paper is to provide Malaysian regulators, practitioners, stakeholders, and reporting companies with additional insights into stakeholder engagement and materiality disclosure in sustainability reporting, which need further development and improvement of policy 
and practice. Malaysian regulators may, therefore, want to formulate more specific and detailed disclosure requirements to achieve greater information disclosure, which, in turn, will advance sustainable development in the public and private sectors.

\section{REFERENCES}

Brundtland, G.H., 1987. Our common future Call for action. Environmental Conservation, 14(04): 291-294. KPMG., 2011. International survey of corporate responsibility reporting. Retrieved from http://www.kpmg.com/au/en/issuesandinsights/articlespublications/pages/kpmginternationalsurvey-corporate-responsibility-reporting-2011.aspx ACCA, 2014. Sustainability matters, ACCA policy paper. Retrieved from http://www.accaglobal.com/content/dam/acca/global/PDFtechnical/sustainability reporting/tech-tp-smapp.pdf

Global Reporting Initiative (GRI), 2013a. G4, Part1, Reporting Principles and Standard Disclosure. Retrieved from http://www.globalreporting.org. Global Reporting Initiative (GRI), 2013b. G4, Part2, Implementation Manual. Retrieved from http:// www.globalreporting.org. Journal of Auditing, 4(3): 247-268.

Lamberton, G., 2005. Sustainability accounting-a brief history and conceptual framework. In Accounting Forum, 29(1): 7-26.

Daub, C.H., 2007. Assessing the quality of sustainability reporting: an alternative methodological approach. Journal of Cleaner Production, 15(1): 7585 .

Bursa Malaysia Securities Berhad, 2016. Sustainability reporting guide and toolkits. Retrieved from http://www.bursamalaysia.com/market/sustainability/sustainabilityreporting/sustainability-reporting-guide-and-toolkits/ GreenBiz, 2014. 4 top sustainability reporting trends for 2014. Retrieved from http://www.greenbiz.com/blog/2014/02/20/top-sustainability-reportingtrends-2014.

Unerman, J. and F. Zappettini, 2014. Incorporating materiality considerations into analyses of absence from sustainability reporting. Social and Environmental Accountability Journal, 34(3): 172-186.

Jones, P., D. Comfort and D. Hillier, 2015. Materiality in corporate sustainability reporting within UK retailing. Journal of Public Affairs. Pfeffer, J., and G.R. Salancik, 2003. The external control of organizations: A resource dependence perspective. Stanford University Press.

Adams, C.A., 2002. Internal organisational factors influencing corporate social and ethical reporting: Beyond current theorising. Accounting, Auditing \& Accountability Journal, 15(2): 223-250.

Haniffa, R.M. and T.E. Cooke, 2005. The impact of culture and governance on corporate social reporting. Journal of accounting and public policy, 24(5): 391-430-430. 262-289.

Adams, C.A. and P. McNicholas, 2007. Making a difference: Sustainability reporting, accountability and organisational change. Accounting, Auditing \& Accountability Journal, 20(3): 382-402.

Michelon, G., and A. Parbonetti, 2012. The effect of corporate governance on sustainability disclosure. Journal of Management \& Governance, 16(3): 477-509.

Edgley, C., M.J. Jones and J. Atkins, 2015. The adoption of the materiality concept in social and environmental reporting assurance: A field study approach. The British Accounting Review, 47(1): 1-18.

Whitehead, J., 2016. Prioritizing Sustainability Indicators: Using Materiality Analysis to Guide Sustainability Assessment and Strategy. Business Strategy and the Environment.

Munoz-Torres, M.J., M.A. Fernandez-Izquierdo, J.M. Rivera-Lirio, R. Leon-Soriano, E. Escrig-Olmedo and I. Ferrero-Ferrero, 2012. Materiality analysis for CSR reporting in Spanish SMEs. International Journal of Management, Knowledge and Learning, 1(2): 231-250.

Hsu, C.W., W.H. Lee and W.C. Chao, 2013. Materiality analysis model in sustainability reporting: A case study at Lite-On Technology Corporation. Journal of Cleaner Production, 57: 142-151.

Edgley, C., 2014. A genealogy of accounting materiality. Critical Perspectives on Accounting, 25(3): 255-271.

Bing, N.S. and A. Amran, 2017. The Role of Board Diversity on Materiality Disclosure in Sustainability Reporting. Global Business and Management Research, 9: 96-109.

Fasan, M., and C. Mio, 2016. Fostering stakeholder engagement: The role of materiality disclosure in Integrated Reporting. Business Strategy and the Environment.

Puroila, J., 2015. What really matters? Materiality disclosures in sustainability reporting practices.

Kolk, A., 2008. Sustainability, accountability and corporate governance: exploring multinationals' reporting practices. Business Strategy and the Environment, 17(1): 1-15.

Said, R., Y. Hj Zainuddin and H. Haron, 2009. The relationship between corporate social responsibility disclosure and corporate governance characteristics in Malaysian public listed companies. Social Responsibility Journal, 5(2): 212-226.

Freeman, R.E., 1984. Strategic Management: A Stakeholder Approach. Boston, MA: Pitman.

Lopez-Gamero, M.D., E. Claver-Cortes and J.F. Molina-Azorin, 2011. Environmental perception, management: and competitive opportunity in Spanish Hotels. Cornell Hospitality Quarterly, 52(4): 480-500.

Kaur, A., and K.S. Lodhia, 2014. The state of disclosures on stakeholder engagement in sustainability reporting in Australian local councils. Pacific Accounting Review, 26(1/2): 54-74.

Gable, C., and B. Shireman, 2005. Stakeholder engagement: A three-phase methodology. Environmental Quality Management, 14(3): 9-24.

Mungoni, T.B., 2014. Stakeholder engagement in the determination of materiality for sustainability reporting.

Yusoff, H. and F. Darus, 2012. Environmental Reporting Practices in Malaysia: Is it a Mechanism for Corporate Accountability and Stakeholder Engagement. Malaysian Accounting Review, Special Issue, 11(2): 137-159.

Manetti, G., 2011. The quality of stakeholder engagement in sustainability reporting: empirical evidence and critical points. Corporate Social Responsibility and Environmental Management, 18(2): 110-122.

Vaz, N., B. Fernandez-Feijoo and S. Ruiz, 2016. Integrated reporting: an international overview. Business Ethics: A European Review. Global Reporting Initiative (GRI), 2016. About sustainability reporting. Retrieved from https://www.globalreporting.org/information/sustainabilityreporting/Pages/default.aspx Global Reporting Initiative (GRI), 2006. Sustainability Reporting Guidelines. G3 Version. GRI: Amsterdam. EY., 2016. Value of sustainability reporting. Boston: Ernst \& Young LLP. Retrieved from http://www.ey.com/Publication/vwLUAssets/EY_Value_of_sustainability_reporting/\$FILE/EY-Value-of-SustainabilityReporting.pdf Hillman, A.J. and G.D. Keim, 2001. Shareholder value, stakeholder management, and social issues: what's the bottom line?. Strategic management journal, pp: 125-139.

Gray, R., 2000. Current developments and trends in social and environmental auditing, reporting and attestation: a review and comment. International AccountAbility, 2005. Stakeholder Engagement Standard. AccountAbility: London.

$$
591 .
$$

Cornell, B., and A.C. Shapiro, 1987. Corporate stakeholders and corporate finance. Financial Management, 16(1): 5-14.

Harjoto, M., I. Laksmana and R. Lee, 2015. Board diversity and corporate social responsibility. Journal of Business Ethics, 132(4): 641-660.

Andriof, J., S. Waddock and S.S. Rahman, 2002. Unfolding stakeholder thinking: theory, responsibility and engagement. Greenleaf Publishing. 
[46] Clarkson, M.E., 1995. A stakeholder framework for analysing and evaluating corporate social performance. Academy of management review, 20(1): 92-117.

[47] Prado-Lorenzo, J.M.P., I. Gallego-Alvarez and I.M. Garcia-Sanchez, 2009b. Stakeholder engagement and corporate social responsibility reporting: the ownership structure effect. Corporate Social Responsibility and Environmental Management, 16(2): 94-107.

[48] Nishant, R., M. Goh and P.J. Kitchen, 2016. Sustainability and differentiation: Understanding materiality from the context of Indian firms. Journal of Business Research, 69(5): 1892-1897.

[49] Rao, K., and C. Tilt, 2015. Board composition and corporate social responsibility: The role of diversity, gender, strategy and decision making. Journal of Business Ethics, pp: 1-21. 